\title{
Investigating the foundation of the Amphitheatrum Flavium through the Passage of Commodus
}

\author{
Luciana Orlando ${ }^{1,}$, Giorgio De Donno ${ }^{1}$, Luca Di Giambattista ${ }^{1}$, Lucia Palladini ${ }^{1}$ \\ 1 “Sapienza" University of Rome - DICEA, Rome, Italy
}

Article history

Received September 30, 2016; accepted May 18, 2017.

Subject classification:

Colosseum, Foundation, Structure characterization, GPR.

\begin{abstract}
In this work we present a non-invasive investigation of the Amphitheatrum Flavium, executed using the ground penetrating radar (GPR) technique, with the aim to improve the knowledge of the construction materials and techniques employed for building foundation. Therefore, the mail goal of this work is to achieve quantitative and reliable information for assessing the seismic vulnerability of the structure. The GPR survey was performed through the Passage of Commodus, excavated within the foundation for a length of about $60 \mathrm{~m}$. GPR data were acquired on the floor and on the lateral walls, using different antenna frequencies (80, 200, $600,900 \mathrm{MHz}$ ) as they combine good resolution and depth of investigation. On the floor dataset, we detected three equally-spaced anomalies related to old utilities parallel to the passageway, whose roof is located at a depth of $1 \mathrm{~m}$. In addition to this, the GPR radargrams clearly highlight horizontal layers within the foundation, related to the sequential development of works at the time of construction. GPR dataset acquired on the wall allowed us to detect the thickness of the concrete covering the foundation and to locate the extensions of the structural elements underground. Outside the foundation, the passage is built using bricks, with external walls about $1 \mathrm{~m}$ thick. Therefore, GPR dataset revealed that the foundation of the Colosseum is a heterogeneous multi-layer element, with the presence of cavity networks and buried elements related to the plinths of the load-bearing structures. This work confirmed that foundation was built over time by means of subdivisions into small sectors, probably both in the horizontal and vertical directions.
\end{abstract}

\section{Introduction}

Understanding shape, position and type of the structural elements is crucial when safeguard activities have to be planned for important monuments. This information can be retrieved from historical documents, archaeological studies and invasive and/or non-invasive field investigations. In this sense, geophysical non-invasive techniques are normally preferred, being cost-effective methods that can give a high resolution image of the inner structure [D'Aranno et al. 2016]. Among geophysical methods, ground penetrating radar (GPR), seismic tomography (ST) and electrical resistivity tomography (ERT) are the most used techniques for these purposes. As a matter of fact, each method has strengths and drawbacks depending on intrinsic limitations (loss of resolution, attenuation, etc.), the type of building and construction materials and the desired target.

Seismic tomography methods are used for material characterization being the seismic velocities directly linked to the elastic material stiffness at low strain [Cardarelli et al. 2002, Polymenakos et al. 2005, Mavko et al. 2009, Orlando and Renzi 2013, Pérez-Gracia et al. 2013, Orlando et al. 2015]. Although multidimensional models can be obtained through inversion of tomographic data, this technique is unfeasible in the presence of highly warped or rough surface, due to the low coupling between surface and receivers.

Electrical Resistivity Tomography (ERT) is used for evaluating the conditions of ancient masonry walls and structures [Sass and Viles 2006, Mol and Preston 2010, Tsourlos and Tsokas 2011, Cardarelli et al. 2016]. Ensuring the good coupling between surface and electrodes is also a major limit of this technique, whereas only non-invasive electrodes can be employed (as for the archaeological purposes).

GPR uses the reflection of electromagnetic waves [Fisher et al. 1992, Daniels 2009] to depict the interior of structure. The high frequency electromagnetic 
waves (30-3000 MHz) can provide a high-resolution image together with a good depth of investigation depending on the signal frequency, the electrical permittivity and the electrical resistivity. In detail, an increase of signal frequency improves the resolution and reduces the depth of penetration; a decrease of permittivity induces an increase of the electromagnetic velocity and a decrease of resolution; an increase of resistivity produces a decrease of attenuation. In particular, structures built with sandstone or limestone are characterised by low electric permittivity and high resistivity and those built with brick or tuff by high permittivity and low resistivity [Annan 2009]. Since the thickness of the investigated structures is often limited, GPR can be a reliable tool for their characterization, combining the high resolution with a good penetration [Conyers 2013, Goodman and Piro 2013]. In the best condition, the maximum penetration depth is 30 and $3 \mathrm{~m}$ for 80 and $900 \mathrm{MHz}$ antennas with a resolution of 0.3 and $0.03 \mathrm{~m}$, respectively [Annan 2005]. GPR method has been successfully applied over time to detect and characterize ancient structures [e.g. Berard and Maillol 2007, Orlando and Slob 2009, Cataldo et al. 2012], to highlight anomalous zones within ancient buildings and to assess the inner state of preservation (see Goodman and Piro [2013], for a collection of successful case histories).

The aim of this study is the characterization of the foundation of the Colosseum (Amphitheatrum Flavium), still partially unknown in terms of building technique and material employed, in order to improve the knowledge of the hidden zone related to the foundations and the utilities (water supply and drainage systems). This information is required for assessing the seismic vulnerability of the monument. Among the geophysical methods mentioned above, we select the GPR technique because it provides ultra-high resolution information, being completely non-invasive and allowing the rapid acquisition of large datasets. The main drawback of the GPR is the limited depth of investigation in presence of conductive materials (clay, water, etc.). In this case study, the monument is mainly built with resistive massive rocks (limestone, sandstone, etc.) with a minor quantity of conductive components (bricks, pozzolanic mortar, etc.).

ERT and seismic tomography investigations were discarded due to the high roughness of both floor and walls, preventing a good coupling between receivers/ electrodes and the surfaces.

The survey was conducted in the so-called "Passage of Commodus", built within the foundations of the Colosseum. This passage represents the unique location where it is possible to investigate directly the foundation of the Colosseum. In light of this, we acquired GPR data both on the floor and on the lateral walls in order to obtain vertical and horizontal sections of the foundation, respectively.

This work is a part of a broad geophysical campaign carried out during last years for the seismic characterization of the Colosseum. Given the complexity of the structure, we will narrow our interpretation of the GPR data only to anomalies that can be distinguished with a low degree of uncertainty, discussing for these cases the archaeological implications. At the end, we aim to give quantitative information about the foundation that can be usable for assessing the seismic vulnerability of the monument.

The paper is organized as follows: in Section II we will introduce the archaeological setting and the GPR data acquisition and processing, while in Section III we present the results of GPR data processing and their interpretation and in Section IV discussion and conclusion.

\section{Archaeological Setting And Geophysical Survey}

\subsection{Site description}

The Colosseum, also known as the Amphitheatrum Flavium, is a $188 \times 156$ m elliptical amphitheatre (Figure 1) built under the Flavian dynasty between 72 and 80 A.D.. The weight-bearing structure of the monument is composed of arches and vaults, arranged in three parallel horizontal rings (Figure 1) and four superimposed levels in elevation. The building's toroidshaped foundations are made of opus caementicium, with pozzolanic mortar and chert pebbles [Mocchegiani Carpano 1977]. From early excavation tests and boreholes drilled in this area, the foundations are supposed to be around 12-14 $\mathrm{m}$ thick, with a lower part (5-6 $\mathrm{m}$ ) excavated using trenches and the upper part elevated above the original ground level. The trenches were excavated in natural heterogeneous subsoil (Holocene sand and clay). The whole foundation was realized through concrete casts. Nowadays, the top of the foundation is $0.5-2.0 \mathrm{~m}$ below the actual topographic surface (22-24 m a.s.l). Roman water supply and drainage systems were found within the foundation, even though they are still not entirely mapped [Corazza and Lombardi 2002].

In detail the upper foundation, internally and externally, is bordered by two elliptical retaining walls made of pozzolanic concrete lined with bricks [Rea 


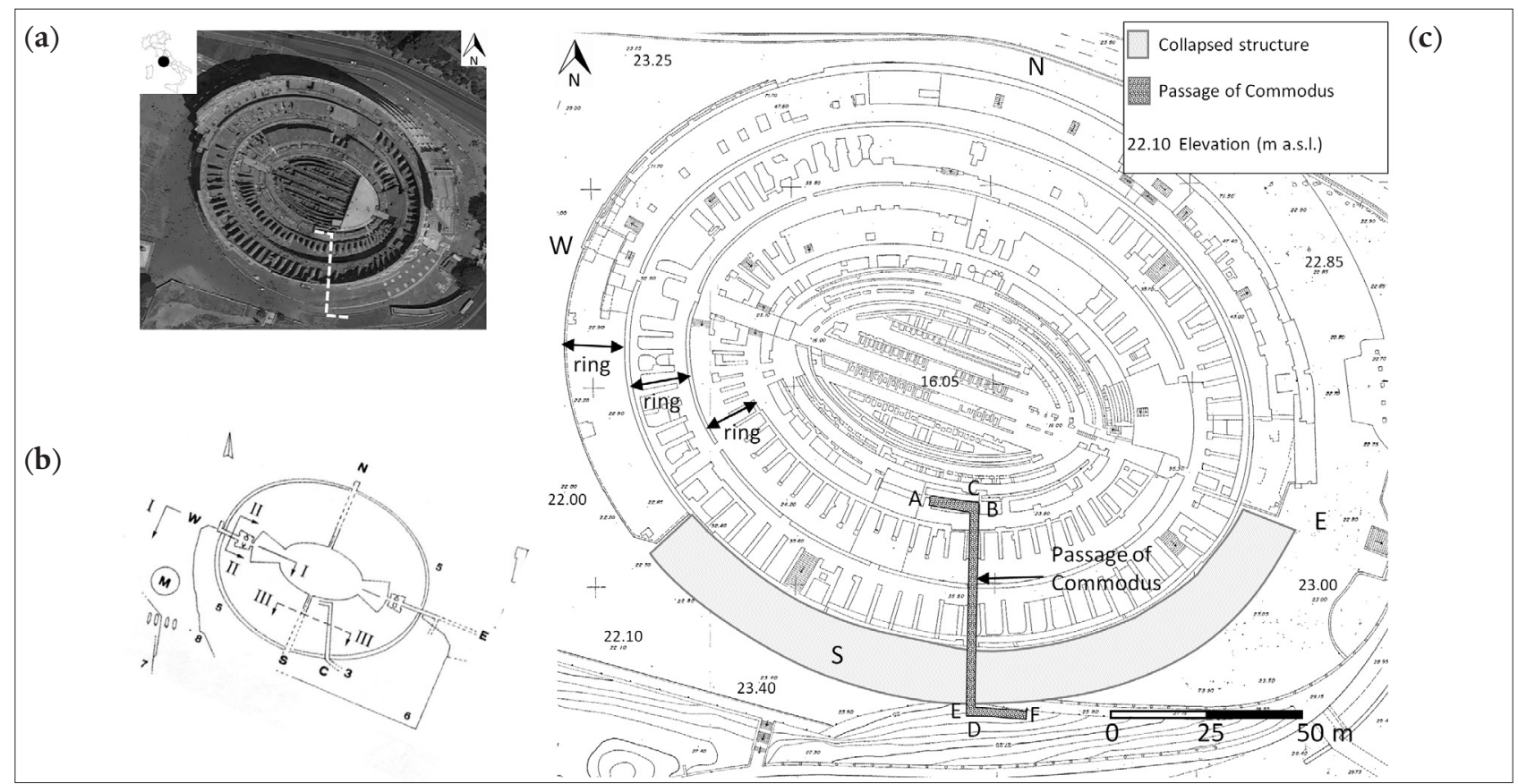

Figure 1. Study area. Aerial view of the Colosseum where the Passage of Commodus is marked with a white dashed line (a). Top view of the foundation (b). Top view of the Colosseum where the Passage of Commodus is superimposed (c).

et al. 2002]. The outer wall is about $6 \mathrm{~m}$ high and $3 \mathrm{~m}$ wide, while the inner wall, more complex than the outer, has a thickness of about $2.3 \mathrm{~m}$. The upper foundation is crossed by five tunnels (Figure $1 \mathrm{~b}$ ), with the four main tunnels, contemporary to the construction, located along the two main axes of the monument, while the fifth tunnel was built later. The four main tunnels divide the upper foundation into four sectors, which in turn were possible sub-divided along radial and elliptic directions by formworks during the construction phase [Rea et al. 2002].

The fifth tunnel, named "Passage of Commodus" (Figure 1), was dug under Emperor Domitian (81-96 $\mathrm{AD})$, as a private passage for the emperor, directly connected to the imperial residence. The passage is radial-directed and extends for about $60 \mathrm{~m}$ from the arena towards south, with a final east-directed part outside the foundation (Figure 1). A sketch of the vertical cross-section of the monument is depicted in Figure 2, while in Figure 3 we show a plan of the Passage of Commodus. The floor elevation difference between the outer and the inner (arena) part of the passageway is around $2 \mathrm{~m}$. The ceilings are brick-made barrel vaults (Figure 4) and both walls and ceilings were originally covered with a thick layer of mortar. However, over time it has been partially removed [La Regina 2001] and nowadays the walls are rough surfaces (Figure 4). Two major earthquakes which occurred in 1349 and 1703 [Molin and Guidoboni 1989], caused the collapse of a large part of the external ring in the southern sec- tor of the Colosseum above the area where the Passage of Commodus is located (Figure 2).

A previous study where GPR data were acquired from the present surface (22-24m a.s.1.), in correspondence of the collapsed structure (Figures $1 \mathrm{c}$ and 4 ), detected the top of the vault of the Passage of Commodus at a depth of 1.5-2.0 m [Orlando 2009].

Therefore, the floor level of the passage is located around 17.5-19.5 $\mathrm{m}$ a.s.l. as previously found by Rea et al. [2002]. Outside the foundation, the passage was built using trenches, removing the travertine pavement covering the top of foundation [Jappelli et al. 2001], with the consequent interruption of the annular drainage system.

\subsection{Data acquisition and processing}

In this work we apply the GPR technique along the Passage of Commodus, both on the floor and on the lateral walls (at a height of $1.5 \mathrm{~m}$ from the floor level). In order to strike a balance between a sufficient depth of investigation and a good degree of resolution, single-fold GPR lines were acquired in continuous mode using different peak-frequency operating with IDS antennas $(80,200,600 \mathrm{MHz}$ on the floor; 200, 600 and $900 \mathrm{MHz}$ on the walls). The passage was divided into three sections, depending on the main direction of acquisition (Figures 2 and 3): AB (12 m long, east-directed), CD (60 m long south-directed) and $\mathrm{EF}$ (12.2 $\mathrm{m}$ long, east-directed).

The GPR dataset was processed through the application of the zero-time correction, a band-pass fre- 


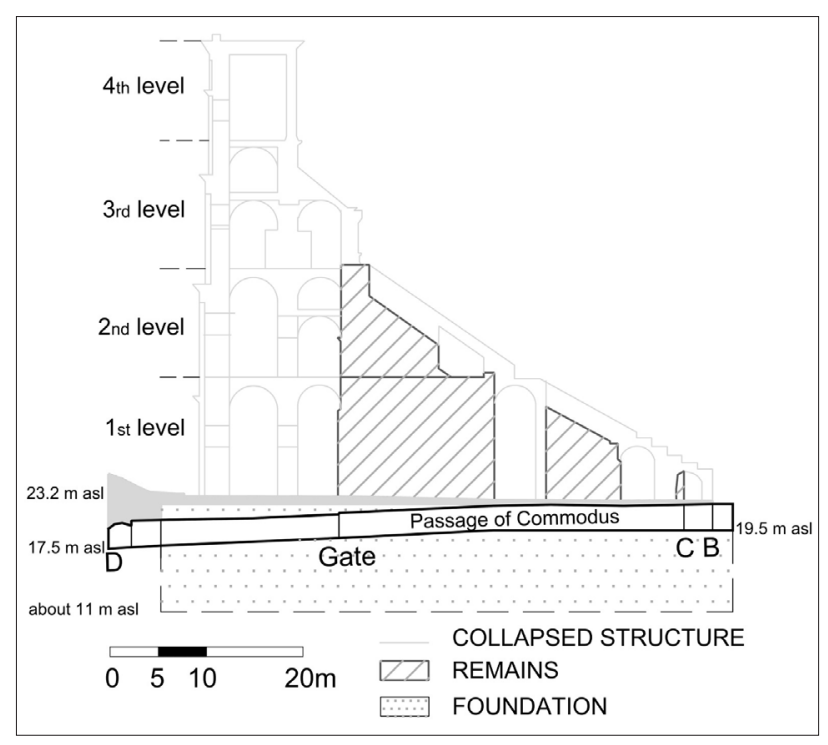

Figure 2. Sketch of the cross-section of the Colosseum along the Passage of Commodus (B-D section).

quency filter and an AGC (Automatic Gain Control) to compensate the spherical divergence and the signal attenuation. The windows selected for ACG and band-pass filters were calibrated depending on data quality and on the antenna frequencies. In detail, the band pass cut-off frequencies was 10-70-200-350, 40100-450-700, 120-200-750-1000 and 150-250-1300-2000 $\mathrm{MHz}$ for 80, 200, 600 and $900 \mathrm{MHz}$ antennas respectively. The propagation velocity of electromagnetic waves was inferred both from Common Mid Points (CMP) acquired on the floor (Figure 3) and from the diffraction hyperbola fitting [Conyers 2013]. The resulting velocity is 7 and $8 \mathrm{~cm} / \mathrm{ns}$ for CMP (Figure 5) and diffraction hyperbola, respectively. Since a detailed velocity profile is not available, we used the mean velocity value of $7.5 \mathrm{~cm} / \mathrm{ns}$ for time-depth conversion in the following interpretation, both for the floor and the walls.

\section{Results}

The results are analysed below as a function of the antenna frequency and on the different type of acquisition: on the floor and on the lateral walls of the Passage of Commodus.

\subsection{Floor}

GPR profiles acquired at the entrance of the Passage of Commodus (AB section in Figures 3 and 4), give an image of the structure up to a depth of 1.875$2.625 \mathrm{~m}$ (Figure 6), depending on the antenna frequency. We noticed a first layer having a thickness of $0.75 \mathrm{~m}$ (white dashed line in Figure 6) overlaying four anomalies (marked as 1, 2, 3 and 4 in Figure 6). The multiple reflections seen in the shallow zones (above the dashed white line in Figure 6) are due to multiple sub-layers related to the pavement (Figure $6 \mathrm{~b}$ ). The main diffraction hyperbolas located at a distance of 1 and $11 \mathrm{~m}$ within the first layer $(5 \mathrm{~ns})$, are probably due to blocks or voids filled by heterogeneous material. The four anomalies detected below the shallow layer are characterized by diffraction hyperbolas for the high-frequency antennas (200 and $600 \mathrm{MHz}$, Figures $6 \mathrm{a}$ and $6 \mathrm{~b}$ ). The anomalies no. 1, 2 and 4 are equally-spaced (around $5 \mathrm{~m}$ ) and located at the same depth $(1.5 \mathrm{~m})$, while the anomaly no. 3 is deeper $(2.5 \mathrm{~m})$ and better detected by the 200 $\mathrm{MHz}$ antenna. Comparing the vertical cross-section of the inner wall of monument [Rea et al. 2002], parallel to the GPR section (Figure $7 \mathrm{a}$ ) with the AB section

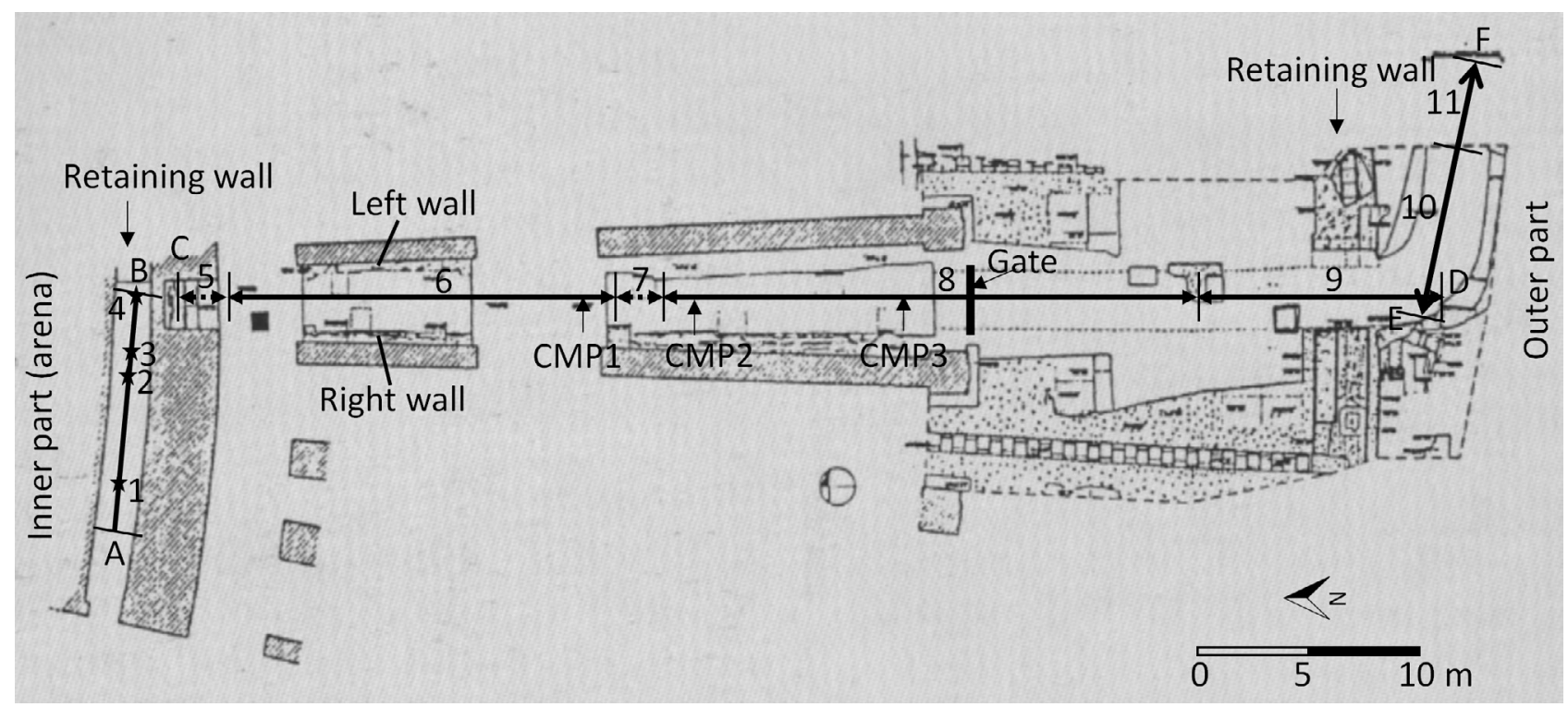

Figure 3. Geophysical survey at the Passage of Commodus, with location of the three sections. Map after Soprintendenza Archeologica di Roma. 

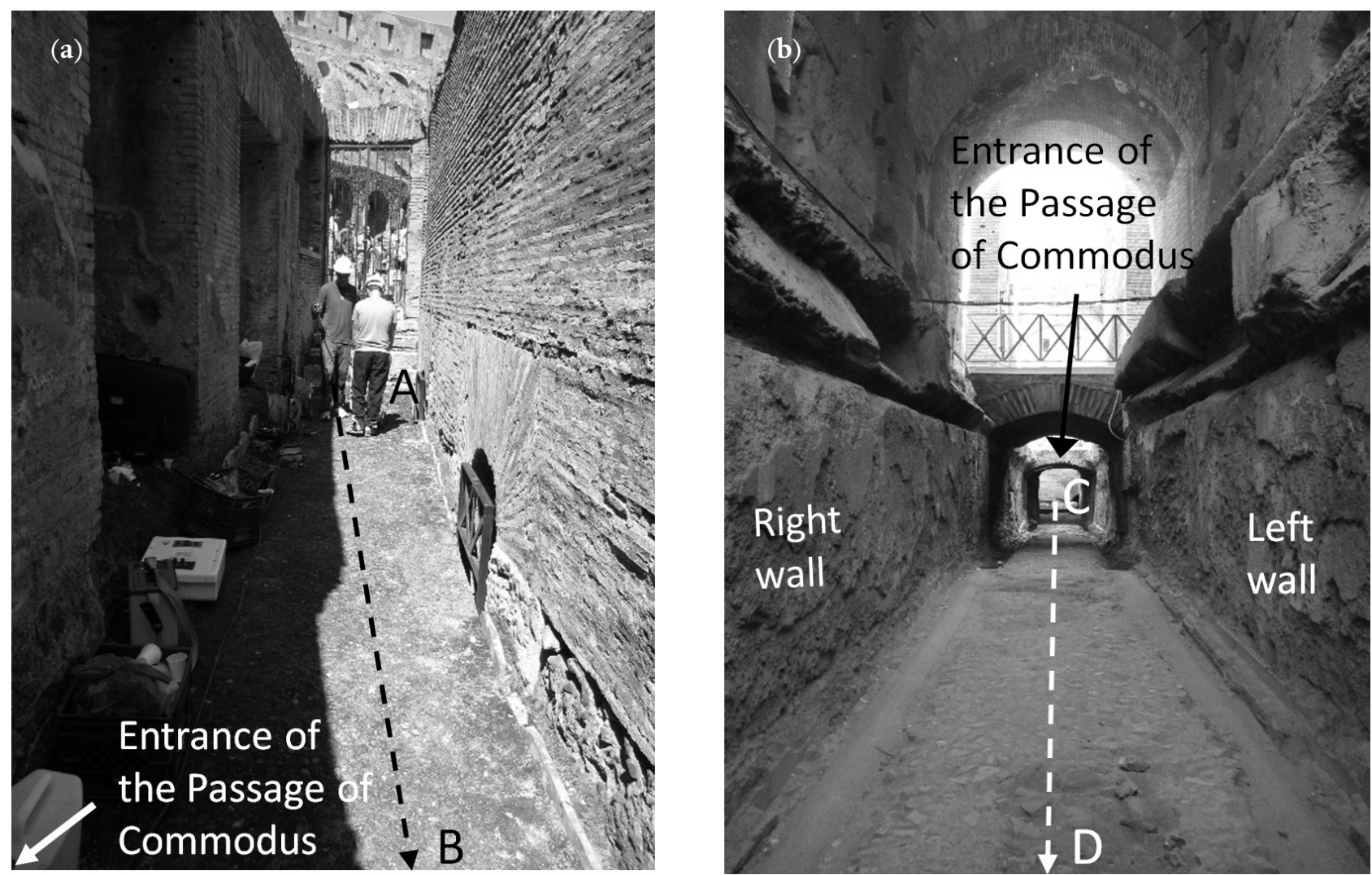

Figure 4. GPR acquisition at the Passage of Commodus. $\mathrm{AB}(\mathbf{a})$ and $\mathrm{CD}(\mathbf{b})$ sections.

(Figure 7b), we find a good correspondence between the structure no. 4 in Figure $7 \mathrm{a}$ and the anomaly no. 4 detected by GPR (Figure 7b). This anomaly can be archeologically interpreted as a service tunnel. Therefore anomalies no. 1 and 2 can also be related to hidden structures similar to no. 4 (large service tunnels).

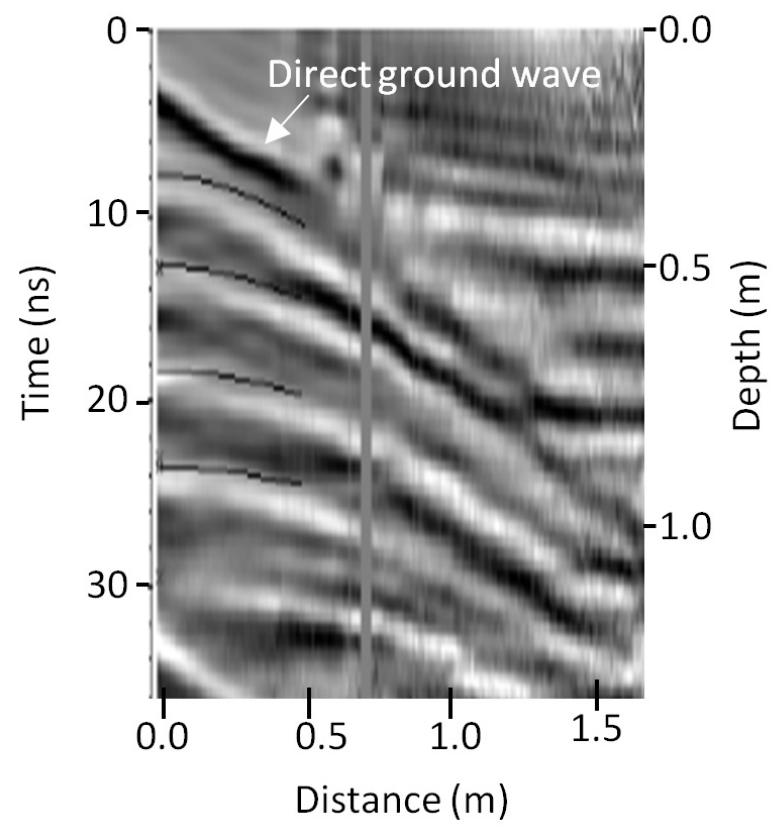

Figure 5. Common Mid Point no.1 acquired on the floor (marked as CMP1 in Figure 3). The electromagnetic wave velocity, estimated by fitting hyperbolas, is equal to $7 \mathrm{~cm} / \mathrm{ns}$.
Without any additional a priori information, we can consider the three equally-spaced anomalies to be a part of a complex system, extended under the floor of the passage. Moreover the anomaly no. 3, smaller and deeper with respect to the others, could be probably due to a radially directed sewer similarly to the anomaly marked with no. 11 in Figure 7a.

Results for the CD section of the passage are represented in Figure 8, as a function of the different antenna frequencies and including the approximated slope of the floor. The maximum signal penetration (40 ns) is reached by the $80 \mathrm{MHz}$ profile, corresponding to a depth of about $1.5 \mathrm{~m}$. The line can be divided in five subsections (no. 5-9), corresponding to different reflection patterns of the GPR investigation. The anomalous zones marked as no. 5 and 7 are interpreted as walls, while in the zone no. 6 , horizontal layers, having similar thickness, are detected (white dotted lines in Figure 8a). The latter is maybe related to the top of a structure embedded in the foundation or to the sub-horizontal layering of the foundation. In fact it is likely that foundations are formed by superimposed layers each of them pertained to different construction phases. The no. 8 zone shows a similar behaviour as no. 6 , even though the layers are truncated on the top right, as the result of the excavation of the Passage of Commodus within the foundation. Therefore, this evi- 

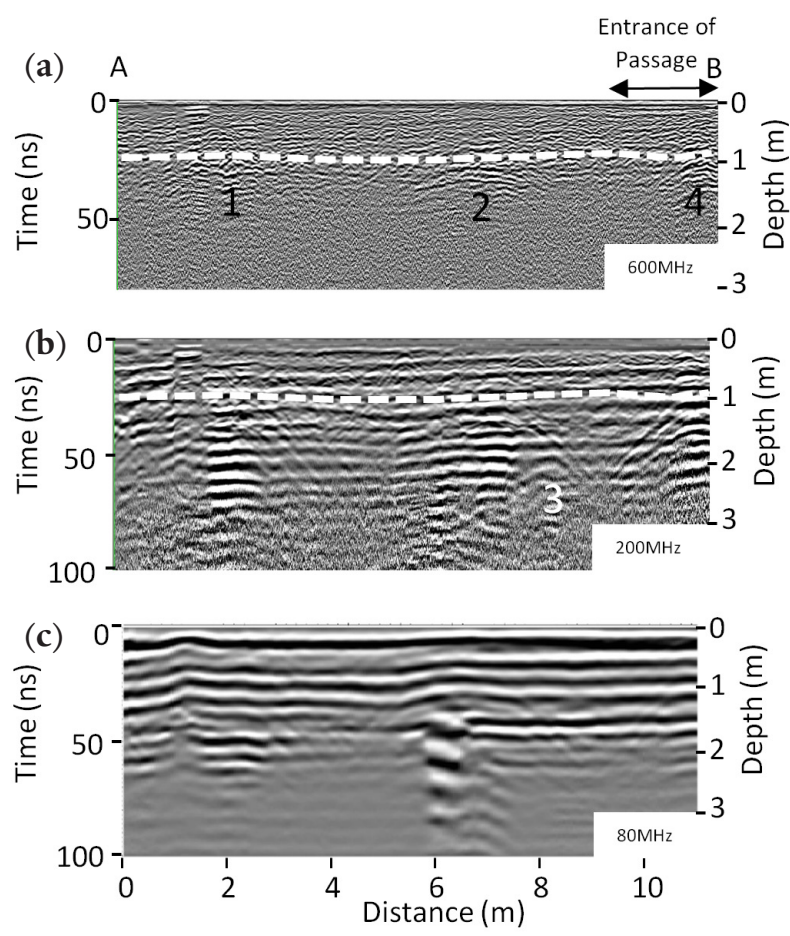

Figure 6. GPR profiles acquired on the floor along the AB section in Figure 3, using 600 (a), 200 (b) and $80 \mathrm{MHz}$ (c) antennas. The white dashed lines represent the level of the cavity network.

dence validates the multi-layer hypothesis for the foundation. At the end we have a more attenuated signal in zone no. 9 with continuous sub-horizontal layers. This effect could be explained by an increase of the electrical conductivity of the subsurface, due to an increase of water content within concrete or to the presence of bricks instead of concrete in that zone.

The investigation of the EF section of the pas- sage, located outside the foundation area (Figure 9), has revealed five main subsections (marked as 10-14 in Figure 9). The zones no. 10 and 12 show also in this case, regular and sharp anomalies which can be interpreted as buried walls, similarly to the zones no. 5 and 7. The contiguous areas (no. 11 and 13) are characterized by high attenuation maybe caused by voids filled with water or by a fine-grained sediment (silt, clay). The final part of the line (zone no. 14) is composed by heterogeneous material pertaining to the base and sub-base layers of the floor, probably located in this zone above filling sediments.

Hence, through this survey we have observed that the maximum depth of investigation is around $3 \mathrm{~m}$ and that foundations are not homogeneous within the range of investigation of the GPR method (0-2 $\mathrm{m}$ from the floor level). This range corresponds to 19.5-17.5 $\mathrm{m}$ a.s.l. for the $\mathrm{AB}$ and the first part (zones no. 5-6) of the CD sections and to 17.5-15.5 $\mathrm{m}$ a.s.l. for the EF profile. Foundations are a multi-layer structure, including buried walls, where each concrete layer has a mean thickness of $0.3 \mathrm{~m}$.

\subsection{Walls}

Each wall (left and right sides of the passage) was surveyed along the $\mathrm{CD}$ section (the investigation of the other sections was unfeasible) with two sub-profiles named C-Gate and Gate-D, due to the presence of a gate between them. Since these lines were executed at a fixed height of $1.5 \mathrm{~m}$ from the floor level, they are located at decreasing depth from the ground level due

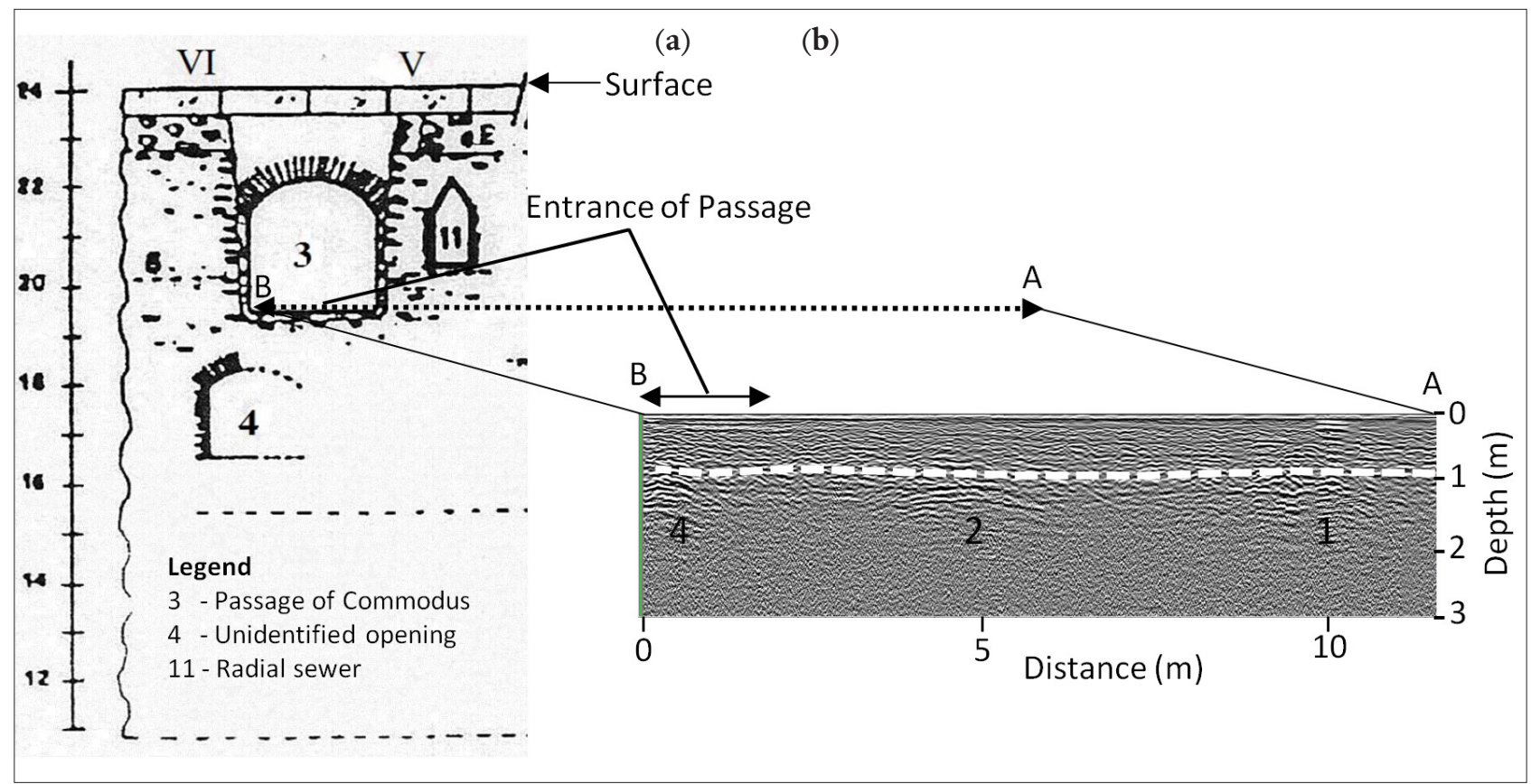

Figure 7. Comparison between the vertical cross-section of the Colosseum (a) normal to the Passage of Commodus (a, after Rea et al. 2002) and the $600 \mathrm{MHZ}$ GPR profile of Figure 6a (b). The superimposition between the two sections is indicated with dotted line. 

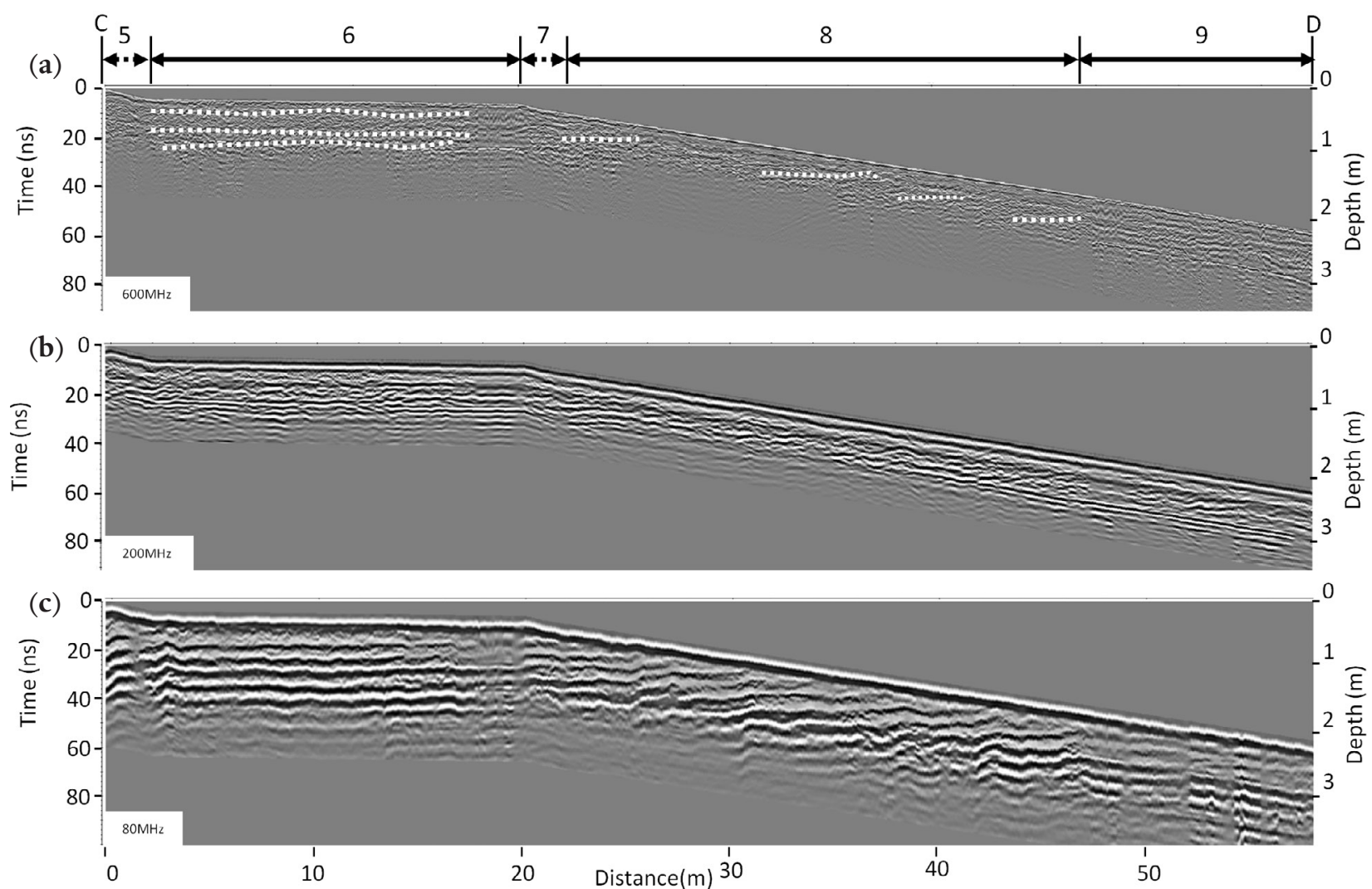

Figure 8. GPR profiles acquired on the floor along the CD section in Figure 3, using 600 (a), 200 (b) and $80 \mathrm{MHz}$ (c) antennas. The white dotted lines represent the foundation layering.
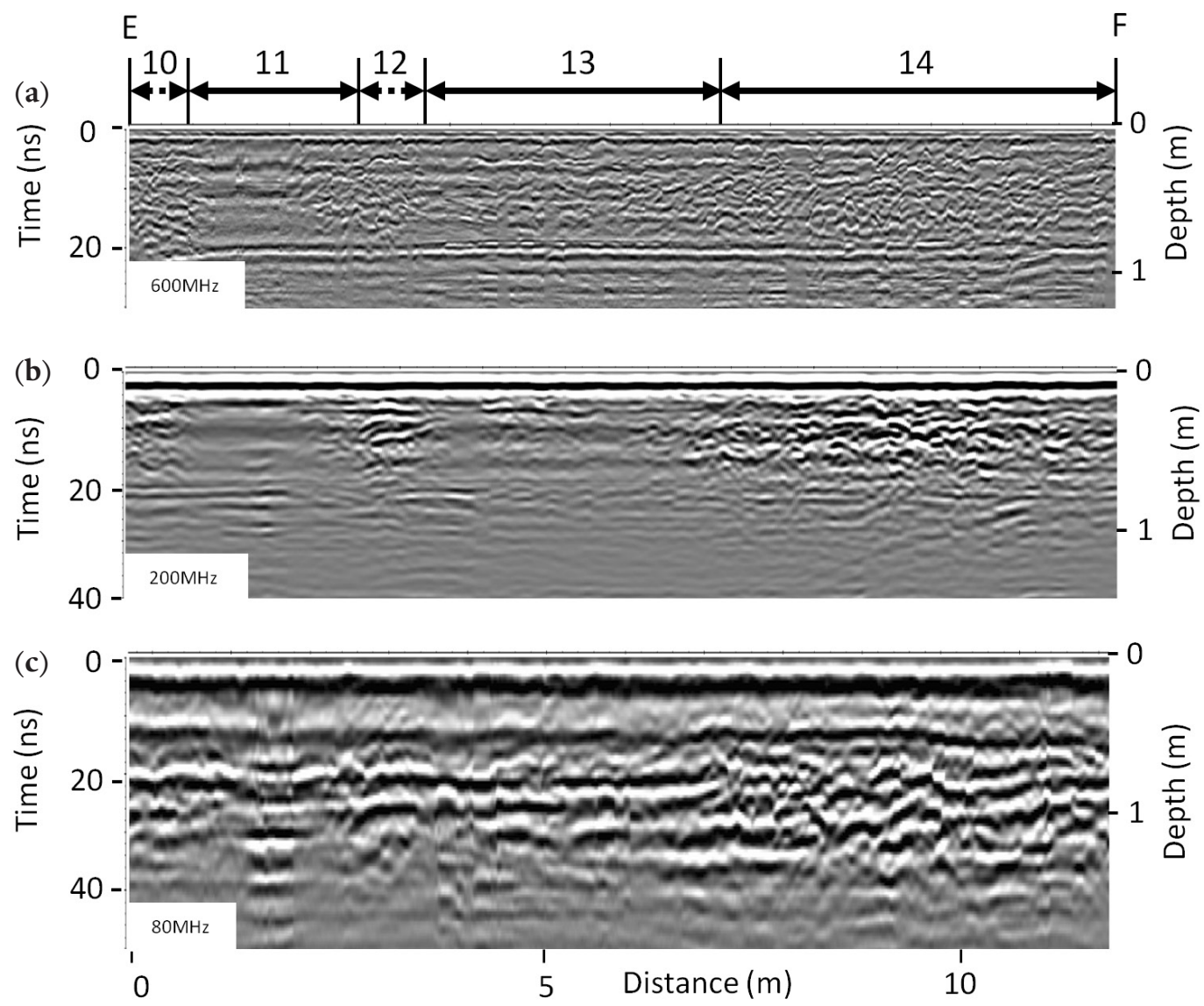

Figure 9. GPR profiles acquired on the floor along the EF section in Figure 3, using 600 (a), 200 (b) and $80 \mathrm{MHz}$ (c) antennas. 

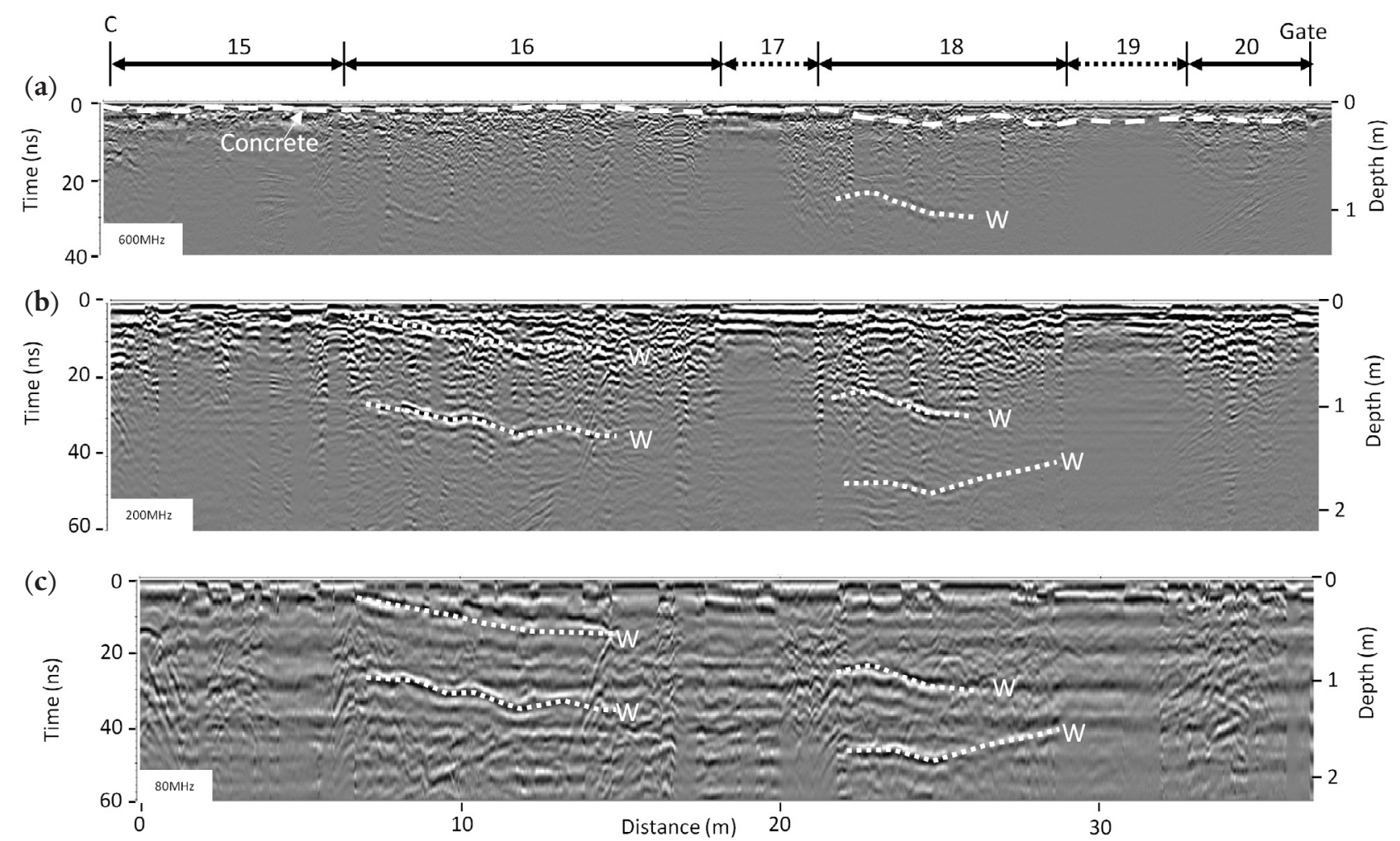

Figure 10. GPR profiles acquired on the left wall along the C-Gate section in Figure 3, using 900 (a), 600 (b) and $200 \mathrm{MHz}$ (c) antennas. The white dotted lines with the capital letter "W", represent the foundation elements, while the mortar/concrete discontinuity is marked with a dashed line.
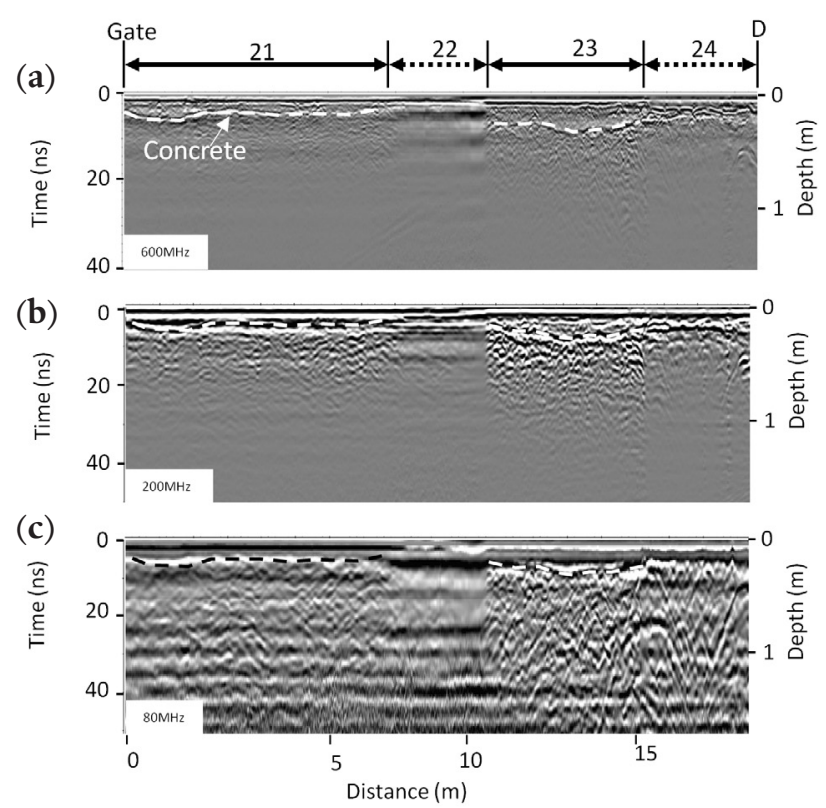

Figure 11. GPR profiles acquired on the left wall along the Gate-D section in Figure 3, using 900 (a), 600 (b) and $200 \mathrm{MHz}$ (c) antennas. The dashed line represent the mortar/concrete discontinuity.

to the above mentioned slope of the floor from the inner to the outer part of the monument.

GPR dataset acquired on left wall along the C-Gate profile (Figure 10) reaches a maximum lateral penetration of $1.87 \mathrm{~m}(50 \mathrm{~ns})$. Here we detect six different sub-sections labelled with no. 15-20. A shallow reflection (few nanoseconds) can be seen continuously along the line (white dashed line in Figure 10), with an increasing thickness from $22 \mathrm{~m}$ to the end of the line. This reflection is probably due to the interface between the mortar covering the wall and the concrete of the foundation. The zones no. 15, 17 and 19 are characterized by a high attenuation that prevents any identification of deeper anomalies. The reflections, marked with letter W in Figure 10, can be due to the extension of the pillars in depth, below the ground level.

The second GPR sub-profile (Gate-D) of the left wall (Figure 11), allows us to identify four different zones (no. 21-24 in Figure 9). Zones no. 21, 22 and 24 are characterized by a strong signal attenuation. In these zones we cannot distinguish any clear reflection, except for the shallow mortar/concrete interface due to the covering (dashed line in Figure 11a). The zone $n$. 23 displays a similar behaviour of the anomalies no. 1618 in Figure 10, as a consequence of the presence of a vertical discontinuity (dotted line), as seen before. The sharp transition between zones no. 23 and 24 could be due to the interface between the foundation and the outer $3 \mathrm{~m}$ thick retaining wall of the foundation. 

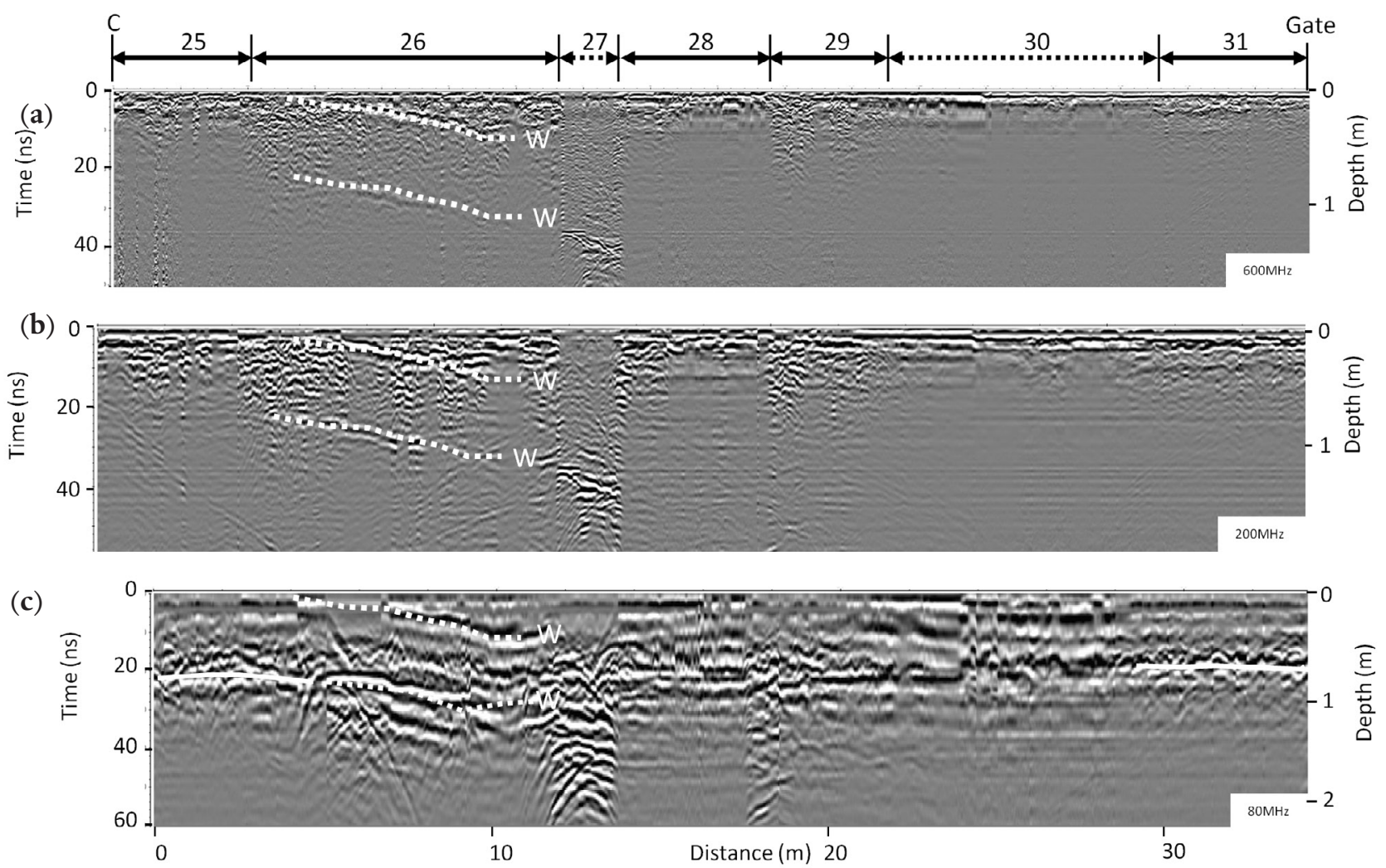

Figure 12. GPR profiles acquired on the right wall along the C-Gate section in Figure 3, using 900 (a), 600 (b) and $200 \mathrm{MHz}$ (c) antennas. The white dotted lines with the capital letter "W" represent the foundation elements.
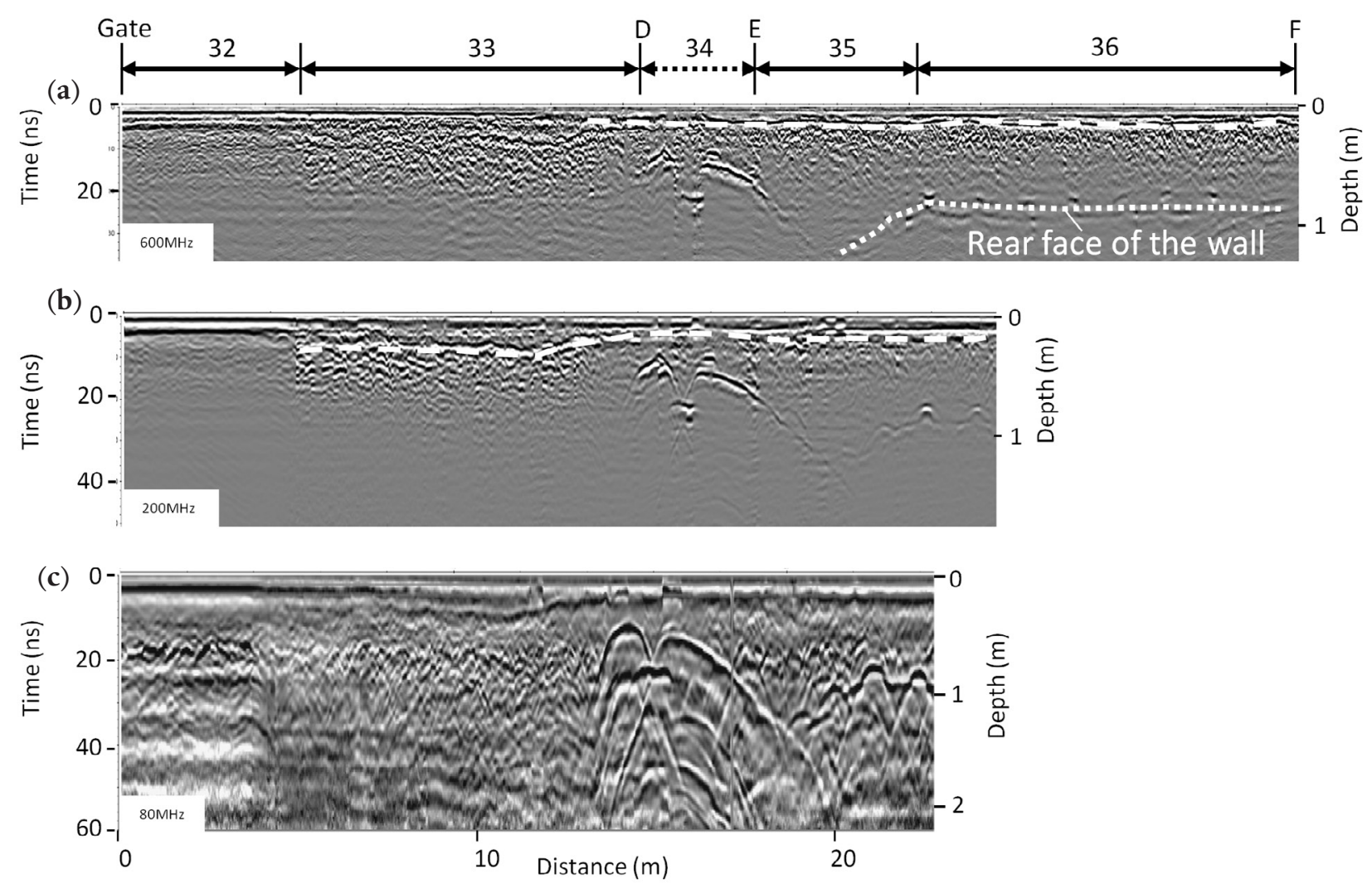

Figure 13. GPR profiles acquired on the right wall along the Gate-D section in Figure 3, using 900 (a), 600 (b) and $200 \mathrm{MHz}$ (c) antennas. The white dotted lines represent the location of the back face of the wall, while the mortar/concrete discontinuity is marked with a dashed line. 
Figures 12 and 13 show the results of GPR investigation on the right wall of the passage. We find a better penetration in the first part of the passage than in the second one. Through the first sub-profile (C-Gate, Figure 12), only reflections from one plinth are detected (zone no. 26), comparable to the evidences of Figure 10 (no. 16). The low signal penetration in the remaining zones prevents the identification of clear anomalies, so the equivalent of the zone no. 18 is not found on the right wall. The reflection marked with a solid white line (Figure 12c) is probably due to the rear face of a bricks wall.

The GPR profile of Figure 13 has been performed on the Gate-D sub-section and partially in the outer part of the passage (EF section), although only with the $900 \mathrm{MHz}$ antenna. We observe a good correspondence in terms of shape and position (about $50 \mathrm{~cm}$ laterally) between the reflection identified in zone no. 33 (white dotted line in Figure 13) and the respective on the left wall (Figure 11, no. 23). Then the DE segment (zone no. 34) depicts the external retaining wall of the foundation including the sewer (strong reflection at $25 \mathrm{~ns}$ ). The zone no. 35 is on the sharp bend of the tunnel, while the zone no. 36 is related to the external part of the passage, parallel to the outside ring of the foundation. In this area, only surveyed with the $900 \mathrm{MHz}$ antenna (Figure 13a) the whole structure of the passage is well detected. On the back face of the wall (reflection at $30 \mathrm{~ns}$ ), equally-spaced $(1.4 \mathrm{~m})$ diffraction hyperbolas are present, likely related to structural elements or to recent reinforcements of the passage. The calculated thickness of the passageway wall, built outside the foundation zone, is around $1 \mathrm{~m}$.

\section{Discussion and conclusion}

The performed measurements inside the Passage of Commodus provide a unique opportunity to retrieve information about the monument foundations since it is the only place where it is possible to directly explore the foundations. The GPR method was applied on the floor and the lateral walls of the Passage of Commodus with the aim to improve the knowledge on building construction techniques and materials of the foundation of the Colosseum. Although the bottom of the foundation was not reached, important information about type and shape of the foundation and about the presence of utilities or cavities underneath the passage and laterally has been retrieved through the aid of this non-invasive technique.

Firstly using the "floor" survey we can split the subsurface below the Passage of Commodus into three different zones: starting from the inside (arena) to the outside of the monument, the first part of the passage (25-30 $\mathrm{m})$ is located above equally spaced $(5 \mathrm{~m})$ voids or cavities. Probably the cavities are related to service tunnels or passages, similar to those detected by Rea et al. [2002] on the foundation walls facing the arena. Then, between 30 and $55 \mathrm{~m}$, the passage was excavated within the foundation. Here the foundation is horizontally stratified with $0.3 \mathrm{~m}$ thick layers. The layers are due to the sequential development of works at the time of construction. In addition to this, the relatively low GPR signal penetration confirms that foundations are made of conductive materials, in agreement with the construction technique (opus caementicium, where pozzolanic mortar is a conductive element). At the end of the passage, outside the foundation, the subsurface is highly heterogeneous, even if not stratified, with the presence of voids and cavities.

The "wall" survey confirms the results obtained on the floor, adding more information about vertical anomalies. Along the south-directed section of the passageway we found multiple reflections, which we related to the continuation of pillars underneath the ground. Outside the foundation, we are able to identify the retaining wall (having a thickness of about $3 \mathrm{~m}$ ), built at the time of construction for the upper foundation, to assess the thickness of the tunnel walls $(1 \mathrm{~m})$ and to individuate reinforcements, spaced $1.4 \mathrm{~m}$ apart, on the rear face of the walls.

Therefore, we have demonstrated that the foundation of the Colosseum is a heterogeneous multi-layer structure, with the presence of a cavity network and of buried structures, due to the extension of load-bearing structural elements underground. This feature confirms that foundation was built over time by means of subdivisions into small sectors, maybe in both directions (horizontal and vertical) where often also vertical bodies are present.

This work has shown the capability of the GPR technique to investigate the foundation of the Colosseum using the antenna directly coupled with the structural element. This information was not retrieved during the single-fold GPR survey performed on surface over the last few years. Future works should include, if feasible, the validation of this result by merging together the results of different archaeological campaigns in progress and by using micro-invasive techniques in the Passage of Commodus (for example performing ERT on the floor with micro-electrodes, which have small diameters, like nails, to ensure a good coupling) and multi-fold GPR acquisition to improve the depth of investigation . 
Acknowledgements. The authors wish to thank the Soprintendenza Speciale per i Beni Archeologici di Roma for permitting the geophysical survey and Fabio Pannone (M.Sc. student - "Sapienza" University of Rome) for the help during field data acquisition.

\section{References}

Annan, A.P. (2005). Ground penetrating radar in D.K. Butler (Editor) Near-Surface Geophysics, SEG. Investigation in Geophysics, 357-438.

Annan, A.P. (2009). Electromagnetic principles of ground penetrating radar in H.M. Joil (Editor) Ground Penetrating radar: Theory and applications, Elsevier.

Berard, B.A. and Maillol, J.M. (2007). Multi-offset ground penetrating radar data for improved imaging in areas of lateral complexity - Application at a Native American site, Journal of Applied Geophysics, 62, 167-177.

Cardarelli, E., Godio, A., Morelli, G., Sambuelli, L., Santarato, G. and Socco, L.V. (2002). Integrated geophysical surveys to investigate the Scarsella vault of St. John's Baptistery in Florence, The Leading Edge, 21(5), 467-470.

Cardarelli, E., De Donno, G., Scatigno, C., Oliveti, I., Martinez, M.P. and Prieto-Taboada, N. (2016). Geophysical and geochemical techniques to assess the origin of rising damp of a Roman building (Ostia Antica archaeological site), Microchemical Journal, 129, 49-57.

Cataldo, R., D’Agostino, D. and Leucci, G. (2012). Insight into the buried archaeological remains at the Duomo of Lecce (Italy) using Ground Penetrating Radar surveys, Archaeological Prospection, 19(3), 157-165.

Conyers, L.B. (2013). Ground penetrating radar for archaeology. AltaMira press, UK, pp.241.

Corazza, A. and Lombardi, L. (2002). L'impianto idraulico in La valle del Colosseo attraverso i secoli Rota Colisei, ELECTA Editor, 46-65.

Daniels, D.J. (2009). Ground Penetrating Radar, 2nd ed, IET, 734.

D’Aranno, P.J., De Donno, G., Marsella, M., Orlando, L., Renzi, B., Salviani, S., Santarelli, M.L., Scifoni, S., Sonnessa, A., Verri, F. and Volpe, R. (2016). High-resolution geomatic and geophysical techniques integrated with chemical analyses for the characterization of a Roman wall, Journal of Cultural Heritage, 17(1), 141-150.

Fisher, E., George, M. and Annan, P. (1992). Acquisition and processing of wide-aperture ground penetrating radar data, Geophysics, 57(3), 495-504.
Goodman, D. and Piro, S. (2013). GPR Remote Sensing in Archaeology, Springer, Berlin, 233.

Jappelli, R., Rea, R., Schingo, G. (2001). Artificial openings in the foundation of the Coliseum, Progress in Tunnelling after 2000, Milan, Italy.

La Regina, A. (2001). Sangue e arena, Mondadori Electa, Milan, Italy.

Mavko, G., Mukerji, T. and Dvorkin, J. (2009). The rock physics handbook: Tools for seismic analysis of porous media, Cambridge University Press, UK.

Mocchegiani Carpano, C. (1977). Nuovi dati sulle fondazioni dell'Anfiteatro Flavio. Antiqua, II-7.

Mol, L. and Preston, PR. (2010). The writing's in the wall: a review of new preliminary applications of Electrical Resistivity Tomography within archaeology, Archaeometry, 52(6), 1079-1095.

Molin, D. and Guidoboni, E. (1989). Effetto fonti, effetto monumenti a Roma: i terremoti dell'antichità a oggi. In: i Terremoti prima del Mille in Italia e nell'Area Mediterranea, E. Guidoboni (Editor), SGA, Bologna, Italy, 194-223.

Orlando, L. (2009). Multi-fold GPR data for the study of foundation of Flavi's amphitheatre. Proceeding of IWAGPR2009, Granada Spain 2007, 155-158.

Orlando, L., Cardarelli, E., Cercato, M. and De Donno, G. (2015). Characterization of a Pre-Trajan wall by integrated geophysical methods, Archaeological Prospection, 22(3), 221-232.

Orlando, L. and Slob, E. (2009). Using multicomponent GPR to Monitor Cracks in a Historical Building, Journal of Applied Geophysics, 67, 327-334.

Orlando, L. and Renzi, B. (2013). Non-destructive Testing for the Characterization of Moai Statues (Easter Island, Chile), Archaeological Prospection, 20 (1), 23-37.

Pérez-Gracia, V., Caselles, J.O., Clapes, J., Martinez, G. and Osorio, R. (2013). Non-destructive analysis in cultural heritage buildings: evaluating the Mallorca cathedral sup-porting structures, NDT \& E Int., 59, 40-47.

Polymenakos, L., Papamarinopoulos, S., Miltiadou, A. and Charkiolakis, N. (2005). Investigation of the foundations of a Byzantine church by three-dimensional seismic tomography, Journal of Applied Geophysics, 57(2), 81-93.

Rea, R., Beste, H.J. and Lancaster, L.C. (2002). Il cantiere del Colosseo. Cantieri Antichi, 341-375.

Sass, O. and Viles, H.A. (2006). How wet are these walls? Testing a novel technique for measuring moisture in ruined walls, Journal of Cultural Heritage, 7(4), 257-263. 
Tsourlos, P.I. and Tsokas, G.N. (2011). Non-destructive Electrical Resistivity Tomography Survey at the South Walls of the Acropolis of Athens, Archaeological Prospection, 18(3), 173-186.

*Corresponding author: Luciana Orlando,

Sapienza, University of Rome - DICEA, Via Eudossiana, 18,

Rome, Italy

email: luciana.orlando@uniroma1.it

2017 by Istituto Nazionale di Geofisica e Vulcanologia.

All rights reserved 